\title{
Strategic Options on Performance of Hunger Safety Net Program among Pastoralists Communities in Turkana County; Kenya
}

\author{
Pascal Ewesit Ekaale ${ }^{1} \quad$ Bula Hannah Orwa, $\mathrm{PhD}^{2}$ \\ 1.School of Business, Strategic Management - Kenyatta University, Nairobi Kenya \\ 2.School of Business, Human Resource Management - Kenyatta University, Nairobi Kenya
}

\begin{abstract}
More than 1.5 million Kenyans in regions that practice pastoralism face chronic food insecurity. As such, the hunger safety nets, which are guaranteed, predictable, timely, as well as multi-year cash transfers to the vulnerable was initiated. However, the existence of this program in Turkana County for more than 10 years has had minimal economic impacting the lives of the people. To unravel the reasons behind this minimal impact, the study was underpinned by these objectives: to determine effects of strategic planning on the performance of hunger safety net program; to establish the influence of strategic control on the performance of hunger safety net program. The study employed the theory of Change, Livelihood Portfolio Theory Based on the Welfare Pentagon, Program theory, Systems Theory and Resource Dependency Theory to elucidate its theoretical underpinnings. It used cross-sectional survey design and targeted the institutions tasked with coordination and payments. The study obtained the respondents through census from National Drought Management Authority (NDMA) and Equity Bank in Turkana County. The sample size consisted of 40 respondents, consisting of senior and middle level managers acquired through primary data collected using structured questionnaires. This study employed content and construct validity while reliability of the research instrument was tested using the Cronbach's alpha coefficient and yielded a value of 0.73 . Data was analysed in two parts: descriptive statistics (mean, standard deviation, frequency and percentiles) and inferential statistics (multiple regression, factor analysis and Pearson's correlation).The study revealed that strategic planning influences the performance of hunger safety net program while strategic control, technology adoption and strategic alliance do not. The study recommended that NDMA and Equity Bank should enhance implementation of their strategic control, strategic alliance and technology adoption in order for these options to spur performance and sustainability of hunger safety net program in Turkana County.
\end{abstract}

Keywords: Strategic Options, Performance, Hunger Safety Net Program and Pastoralism.

DOI: $10.7176 / \mathrm{EJBM} / 12-32-03$

Publication date: November $30^{\text {th }} 2020$

\subsection{Introduction}

The Hunger Safety Net program (HSNP) is a social cash transfer program whose main objective is to reduce extreme poverty and build resilience levels of the vulnerable people in the society. Most evidence on how social protection programs impact on poor and middle-income nations originates from Latin American on conditional cash transfer programs, of which many have undergone vigorous evaluation (Goeury, 2016). Similar programs instituted in Latin America in the 1980s resulting in improved health, nutrition, reduction of poverty gap, increased school enrolment and reduced wealth inequalities (Riches \& Silvasti, 2014).

India and Bangladesh also have important social protection offers, although such benefits have been in form of short-term cash transfers, or food and cash, and with limited coverage as the pilot tests were done to assess the possible impact of the program that would extend to cover more areas over time (International Food Policy Research Institute, 2009)

In fragile nations, safety nets are at their starting stages, with South Africa practicing social protection in the context of HIV-AIDS and Ethiopia undertaking productive safety net program (PSNP) (Rebecca, 2007). In Zambia, there are cash transfers, which affect the quantity of food as well as dietary diversity among the beneficiaries (HelpAge International, 2005).

The current levels of economic depreciation in Kenya are staggering, with about $47 \%$ of the population living below the poverty line and about $20 \%$ of Kenyans living in extreme poverty (Beesley, 2011). Over 1.5 million of the Kenyans face chronic food insecurity and are dependent on food relief for survival. Many of the vulnerable households to food insecurity are located in the arid and semi-arid lands (ASAL), covering about 80 per cent of Kenyan land area (Abdu, 2015).

Most of these residences in ASAL counties practice pastoralism. According to Huho, Ngaira and Harun (2011), pastoralism is an essential economy in the world's dry lands and supports lives as well as livelihoods of approximately 120 million pastoralists globally who keep goats, camels, cattle and sheep. Pastoralism in the Kenyan dry lands stands for 90 percent of employment and 95 percent of income for families and household securities. According to Haji (2014), scarce resources, particularly water and rainfall, rainfall fluctuations along with recurrent drought episodes and thus high human pressure on these resources, characterize the pastoralists 
regions. The resources run out during severe drought, the pastoralists traverse large areas searching for pasture and water, and failure to access enough water, and pasture leads to loss of numerous livestock as well as loss of human life due to poverty conditions.

The HSNP in Kenya aims at reducing chronic shocks, which characterize the pastoralist communities in Northern Kenya. HSNP was implemented in Mandera, Marsabit, Turkana, and Wajir Counties since the year 2009, and still continues to develop the people's livelihoods at the start, the program targeted 69,000 households of beneficiaries, approximately 496,800 people and it made cash transfer of Kshs. 2,150 per household and the amount was later raised to Kshs. 3,500 (Attahet al., 2012). The pilot phase received funding from the state, donors, NGOs, and the civil society. Turkana County registered households 137,534 and the targeted households were 39,918 .

\subsection{Statement of the Problem}

Despite the existence of Hunger Safety program in Turkana County for more than 10 years, it is not clear whether the living conditions of people in Turkana have improved. People from Turkana County always suffer from food insecurity and livestock diseases that affect the ability of the people to cope (Beesley, 2011) and poverty index is at 79.4 percent compared to a national average of 31.6 percent and thus necessitating the intervention through social protection(KIHBS report, 2018).

Strategic options have important performance implications and are generally linked to the environment (Senaratne \& Wijesiri, 2008). Strategic planning gives a clear direction and involves specification of the objectives of the organization, development of plans to achieve objectives, as well as prudent allocation of resources.

Ali (2018) studied the influence of strategic planning on organizational performance by reviewing as well as analysing a total of 15 previous studies as well as literature from well-chosen electronic academic resources and databases. The study concluded that influence of strategic planning on organizational performance differs and conflicting in unstable environment and thus the current study took an in-depth exploration on the relationship between strategic planning and HSNP's performance in Turkana County.

Strategic control ensures that strategic plans become a reality (Kuye, 2013). It ensures the absence of confusion and unethical practices in organizations as it allows the management to step back, look at the big picture, and ensure that all the pieces are aligned correctly. Gaturu (2017) examined the influence of strategic control on organizational performance of Mission Hospitals in Kenya. The study findings showed that strategic control is one of the major practices in mission hospitals in Kenya and it is an important tool in enhancing organizational performance. However, the study was limited to strategic control in mission hospitals in Kenya and did not offer sufficient diversity. This presented a need for a study to establish strategic control on performance of HSNP in Turkana County.

From the above discussions, it therefore shows that there are varied results on the strategic options on performance of hunger safety net program among pastoralists' communities in Turkana, Kenya. In light of this, the current study sought to unearth the strategic options on performance of Hunger Safety Net Program among pastoralists' communities in Turkana County, Kenya.

\subsection{Main Research Question}

Do strategic options influence the performance of hunger safety net program in Turkana County?

\subsection{Specific Research Questions}

i. What is the effect of strategic planning on the performance of hunger safety net program in Turkana County?

ii. How does strategic control influence the performance of hunger safety net program in Turkana County?

\subsection{Literature Review}

Ali (2018) studied the influence of strategic planning on organizational performance by reviewing as well as analysing a total of 15 previous studies as well as literature from well-chosen electronic academic resources and databases. The findings indicated that there were inconclusive findings correlating strategic planning and organizational performance. Eight of the chosen studies indicated presence of relationship, although the findings from many of these studies are inconclusive. Three of the chosen studies wholly indicated that there is positive relationship while four others found no significant relationship. The majority of those empirical studies propose the non-existence of the relationship. The study concluded that the effects of strategic planning on organizational performance is not linear and at times contradictory in unstable environment and thus the current study sought to establish the relationship between strategic planning and performance of HSNP in Turkana County.

Kiramana (2017) conducted a case study on the impact of strategic planning on organizational performance of Equity Bank of Kenya. The study collected primary data using an interview guide while secondary data was 
obtained from public audited financial reports and publications of Equity Bank. The study findings revealed that Equity Bank adopted several strategic objectives including diversification, new product development strategy, digitalization strategy, and market penetration strategy that has resulted in continuous increment of performance of Equity Bank every year as measured using growth of asset base, profitability, and growth in customer base. It concluded that effective strategic planning bears a positive effect on organizational performance. However, the study was not conclusive whether it is strategic planning alone that contributes to organizational performance thus recommending that further studies be conducted to compare the performance of organizations that use strategic planning and those that do not.

Gaturu (2017) examined the influence of strategic control on organizational performance of Mission Hospitals in Kenya. It applied a mixed methods design, adopting both qualitative and quantitative paradigms. The study used a descriptive design with a target population of 58 mission hospitals in Kenya. The study findings showed that strategic control is one of the major practices in mission hospitals in Kenya and it is an important tool in enhancing organizational performance. However, the study was limited to strategic control in mission hospitals in Kenya, did not offer sufficient diversity, and thus presented the need to study the influence of strategic control on performance of HSNP in Turkana County.

Kamau (2013) examined the strategic control practices by Sygenta Pollen Limited in Kenya. The study collected data through interviewing the respondents who were the top managers in charge of production, implementation of strategy, finance, human resource management and development, and business development. Data collected was analysed using content analysis. The results indicated that strategic control should fit the strategic plan of the organization and that the control practices require a feedback mechanism so that the management can identify deviations from expected operation and at the same time, the deviations should be measurable. However, the study ignored other crucial strategic options, as it was only limited to strategic control. Also, results from a case study cannot be applied to other studies and thus there was need to conduct further research.

\subsection{Methodology}

This section describes the research design, population and sample size, research instruments, validity, reliability and data analysis procedures.

\subsection{Research Design}

A descriptive cross-sectional survey design was adopted in this study. Descriptive study designs help in providing answers to what, where, and how questions regarding the phenomenon under investigation (Creswell \& Creswell, 2017). A descriptive survey was appropriate because the researcher did not influence the information collection when establishing the impact of HSNP on household strategic decisions in Turkana County.

\subsection{Population and Sample}

This study used census method in selecting a sample size of 45 respondents. The study picked 20 senior managers (10 from Equity \& 10 from NDMA) and 15 middle level managers in the two institutions (10 from Equity Bank and15 from National Drought Management Authority (NDMA), making a total number of 45 respondents from the two institutions. The study respondents were obtained from the institutions' branches in Turkana County.

\subsection{Research Instruments}

The study employed primary data obtained via a structured questionnaire. According to Mugenda (2003), a questionnaire has a list of probable choices from which the respondents select the most suitable response that accurately describes the issues under investigation. The questionnaire used a five-point Monadic scale to measure the perception of the constructs by the respondents. This study chose a questionnaire because it is easy to administer

\subsection{Validity and Reliability}

This study employed content and construct validity. Validity of a research instrument describes the accuracy and meaning of inferences of study findings (Mugenda \& Mugenda, 2003). Content validity compared the congruency between test contents and the actual content. The questionnaire achieved content validity by having the items reviewed by the supervisor along with other university experts. The Cronbach Coefficient Alpha yielded a figure of 0.73 which is reliable. This study ensured constructs validity by operationalizing the study variables to realize the theoretical assumptions guiding the conceptual framework. 


\subsection{Data Analysis}

Data was analysed in two steps. The first step involved use of descriptive statistics (frequency, mean, standard deviation, and percentages) to describe the characteristics of data while the second step involved use of inferential/parametric statistics (Pearson's correlation, multiple regression and factor analysis) applying effect sizes ( $r$-values) and significance levels ( $p$-value) as well as Bootstrap confidence level of 95 percent to explicate the relationships between independent and dependent variables in the research questions (Field, 2018).

The major findings of this research are summarized based on two categories: the relationship between strategic planning and performance of hunger safety net program in Turkana County; the relationship between strategic control and performance of hunger safety net program in Turkana County.

\subsection{Demographic Information of the Respondents}

The results of participants' demographic characteristics on gender, age, managerial position, level of education and work experience were reported. The participants comprised $65 \%$ male and $35 \%$ female. Majority $(62.5 \%)$ were in the age group of $25-34$ years. In addition, $4(10 \%)$ of the respondents were in top management positions while $36(90 \%)$ were in mid-level management positions. In terms of education, two participants representing $(5 \%)$ had high school certificates, $7(17.5 \%)$ had diplomas, $27(67.5 \%)$ while $4(10 \%)$ had master degrees. Further, majority $31(77.5 \%)$ of the participants had with the organizations for between $2-10$ years, $6(15 \%)$ had work experience of less than 2 years while $3(7.5 \%)$ had experience of more than 10 years. These demographics reveal that the respondents were young, had college good education to help them properly implement, manage and review the hunger safety net program in Turkana County.

\subsection{Findings on the Effects of Strategic Planning on the Performance of Hunger Safety Net Program in Turkana County.}

The first research question sought to determine the effects of strategic planning on the performance of hunger safety net program in Turkana County. The five point Likert scale was rated from 1.0 to 5.0 with the median being 3.0 as follows: $1=$ Not at all, $2=$ Small extent, $3=$ Moderate extent, $4=$ Larger extent, $5=$ Very large extent. A mean score less than 3.0 denoted that the majority of the respondents agreed that strategic planning had small effect on performance of hunger safety net program while a mean score greater than 3.0 indicated that strategic planning had large effect on performance of hunger safety net program.

Descriptive statistics revealed that the mean scores on the strategic planning ranged from 3.92 to 4.45 . The difference between the highest and the lowest means was 1.16 indicating there were few outliers in the data. Ideally, for the data to obtain its conceptual fit, the range should be close to zero. Further, to ascertain how varied (close or far) the responses were placed in relation to the mean score, standard deviation was calculated and revealed a minimum value of 0.71 and a maximum value of 1.05 . Statistically, this indicated that the respondents agreed that the items on the Likert scale denoted strategic planning on performance of hunger safety net program.

It was important to investigate the effects of strategic planning on the performance of hunger safety net program using Pearson's correlation analysis. This was because, correlation makes no prior assumption as to whether one variable is dependent on the other(s) and is not concerned with the relationship between variables; instead it gives an estimate as to the degree of association between the variables. As such, the researcher applied Pearson's correlation (Bivariate) analysis to establish the inter-dependence between strategic planning and the performance of hunger safety net program. The strength and direction of the relationship was presented as $r$ values (values between -1 and +1 ). The $r$-values were interpreted in line with recommendations provided by Cohen (2018). The effect sizes were rated as follows $r=.10$ denoted small effect, $r=.30$ denoted medium effect, and $r=.50$ denoted large effect. But it is imperative to note that $r$ is not measured in a linear scale.

Table 4.1: Correlation Analysis between Strategic Planning and Performance of Hunger Safety Net Program

\begin{tabular}{llcc}
\hline & & Strategic Planning & $\begin{array}{c}\text { Hunger Safety Net } \\
\text { Program }\end{array}$ \\
\hline \multirow{3}{*}{ Strategic Planning } & Pearson Correlation & 1 & $.321^{*}$ \\
& Sig. (2-tailed) & & .044 \\
& $\mathrm{~N}$ & 40 & 40 \\
Hunger safety net program & Pearson Correlation & $.321^{*}$ & 1 \\
& Sig. (2-tailed) & .044 & 40 \\
\hline
\end{tabular}

The analysis on Table 4.1 indicates that the correlation coefficient was significant at $(r=.321, p=.044)$. This significant $p$-value implies that strategic planning has significant effect on the performance of hunger safety net program because $(p$-value $=0.044<.05)$. In consideration of this, the results show that $r=.321$ which means that strategic planning influences the performance of hunger safety net program by $32.1 \%$, that is $(0.321 * 100)$. As such, strategic planning has a positive medium effect on performance of hunger safety net program and 
should always be part of the HSNP project. This finding is concordant to that of a case study conducted by Kiramana (2017) on the influence of strategic planning on organizational performance of Equity Bank of Kenya. The study concluded that effective strategic planning has a positive effect on organizational performance. The results of multiple regression and factor analysis also revealed that strategic planning influences the performance of hunger safety net program.

\subsection{Findings on the Influence of Strategic Control on the Performance of Hunger Safety Net Program in Turkana County.}

The second research question sought to establish the influence of strategic control on the performance of hunger safety net program in Turkana County. The results of the descriptive analysis revealed that all mean scores were greater than 3.0, indicating that the strategic control had influence on the performance of hunger safety net program to a large extent.

The researcher further applied Pearson's correlation to establish the influence of strategic control on the performance of hunger safety net program among pastoralist communities in Turkana County as presented in Table 4.2.

Table 4.2: Correlation Analysis between Strategic Control and Performance of Hunger Safety Net Program

\begin{tabular}{llcc}
\hline & & Strategic Control & $\begin{array}{c}\text { Hunger Safety Net } \\
\text { Program }\end{array}$ \\
\hline \multirow{3}{*}{ Strategic control } & Pearson Correlation & 1 & .243 \\
& Sig. (2-tailed) & & .131 \\
& $\mathrm{~N}$ & 40 & 40 \\
Hunger safety net program & Pearson Correlation & .243 & 1 \\
& Sig. (2-tailed) & .131 & 40 \\
\hline
\end{tabular}

The results of the analysis in Table 4.2 show that the correlation coefficient between strategic control and hunger safety net program was non-significant at $(r=.243, p=.131)$. This non-significant $p$-value implies that there is no significant relationship between strategic control and hunger safety net program $(p=.131>.05)$. The effect size in Table 4.5 indicates that the correlation coefficient is $r=.243$ which means that there is a small nonsignificant relationship of $24.3 \%(0.243 * 100)$ between strategic control and hunger safety net program. Overall, the results mean that strategic control does not influence the performance of hunger safety net program.

This finding is similar to those of Lin, Chen \& Lin (2017) who carried out a study on the influence of strategic control and operational control on new venture performance in China. The findings of the study revealed that strategic control and operational control have a significant negative association with the performance of new venture. The finding from multiple regression and factor analysis also indicated that strategic control does not influence the performance of hunger safety net program.

\subsection{Multiple Regression Analysis}

After analysing each research question, the researcher performed a multiple regression analysis combining all the two independent variables (strategic planning and strategic control) to predict the performance of hunger safety net program (dependent variable). This was to establish the combined influence of all the two predictors on the performance of hunger safety net program.

Table 4.3: Regression Model Fit

\begin{tabular}{ccccc}
\hline Model & R & R Square & Adjusted R Square & Std. Error of the Estimate \\
\hline 1 & $.371^{\mathrm{a}}$ & .138 & .039 & 3.43620
\end{tabular}

a. Predictors: (Constant), Strategic control, Strategic planning

b. b. Dependent Variable: Hunger Safety Net Program

The results of the analysis in Table 4.3 show that $R=.371$ representing the simple correlation between Predictors (strategic planning and strategic control) and the dependent variable (hunger safety net program). The value of $R^{2}=.138$ implying that the 2 independent variables explain $13.8 \%$ of the performance of hunger safety net program. This is not statistically desirable since regression only explains less than $50 \%$ the variance in performance of hunger safety net program. However, the computation of ANOVA reveals more as shown below. Table 4.4: ANOVA Explaining Regression Model against Mean

\begin{tabular}{llccccc}
\hline & Model & Sum of Squares & Df & Mean Square & F & Sig. \\
\hline \multirow{2}{*}{1} & Regression & 66.113 & 2 & 16.528 & 1.400 & $.254^{\mathrm{b}}$ \\
& Residual & 413.262 & 35 & 11.807 & & \\
& Total & 479.375 & 39 & & & \\
\hline
\end{tabular}

a. Predictors: (Constant), Strategic alliance, Strategic control, Technology adoption, Strategic planning

b. b. Dependent Variable: Hunger Safety Net Program

The results in Table 4.4 indicate that the $F$ statistic is significant $F(2)=1.400, p=.254$. This shows that 
there is only $25.4 \%$ chance that an $F$-ratio of this magnitude would happen if the independent variables (strategic planning, strategic control) had no effect on the dependent variable (performance of hunger safety net program). In overall, this implies that a combination of the two strategic options significantly predicts performance of hunger safety net program well and using the regression model is better than using the mean as the "best guess". Table 4.5: Regression Coefficients

\begin{tabular}{|c|c|c|c|c|c|c|c|c|c|c|c|}
\hline \multirow{2}{*}{\multicolumn{2}{|c|}{ Model }} & \multicolumn{2}{|c|}{$\begin{array}{l}\text { Unstandardized } \\
\text { Coefficients }\end{array}$} & \multirow{2}{*}{$\begin{array}{c}\text { Standardized } \\
\text { Coefficients }\end{array}$} & \multirow[t]{2}{*}{$\mathrm{T}$} & \multirow[t]{2}{*}{ Sig. } & \multicolumn{3}{|c|}{ Correlations } & \multicolumn{2}{|c|}{$\begin{array}{c}\text { Collinearity } \\
\text { Statistics }\end{array}$} \\
\hline & & $\mathrm{B}$ & $\begin{array}{l}\text { Std. } \\
\text { Error }\end{array}$ & & & & $\begin{array}{l}\text { Zero- } \\
\text { order }\end{array}$ & Partial & Part & Tolerance & VIF \\
\hline \multirow{3}{*}{1} & (Constant) & 1.420 & 4.725 & & .300 & .766 & & & & & \\
\hline & $\begin{array}{l}\text { Strategic } \\
\text { Planning }\end{array}$ & .465 & .263 & .363 & 1.765 & .086 & .321 & .286 & .28 & .581 & 1.720 \\
\hline & $\begin{array}{l}\text { Strategic } \\
\text { Control }\end{array}$ & .148 & .154 & .182 & .963 & .342 & .243 & .161 & .15 & .686 & 1.457 \\
\hline
\end{tabular}

a. Dependent Variable: Hunger safety net program

In Table 4.5, the strength and direction of the relationship between independent variables and dependent variable was presented as $\beta$-values (standardized beta coefficients, which are interpreted similarly to correlation coefficients, values between -1 and +1 ). Specifically, the closer to the absolute value of 1 the coefficient is, the stronger the effect of that independent variable on the dependent variable (controlling for other variables in the equation). The closer the coefficient is to 0 , the weaker the effect of that independent variable.

The results in Table 4.5 revealed that strategic planning had the larger absolute standardized coefficient $(\beta$ $=.363, p=.086)$. This means that strategic planning has the strongest positive effect on performance of hunger safety net program (controlling for all other independent variables), followed by strategic control $(\beta=.182, p$ $=.342$ ), which had a small positive non-significant effect on performance of hunger safety net program. The two positive standardized coefficients indicated that strategic planning and control had positive association (direction) on overall performance of Hunger Safety Net Programme.

\subsection{Summary and Discussion of Findings}

The analysis of the first research question revealed that strategic planning has a positive influence of $32.1 \%$ on the performance of hunger safety net program in Turkana County. This is attributed to the ability of strategic planning to steer the program by giving a clear direction and specifying the goals and objectives of hunger safety net program, acting as a blueprint for its development plans, and enabling prudent allocation of resources to successfully implement and meet its objectives.

The analysis of the second research question found out that strategic control does not influence the performance of hunger safety net program in Turkana County. Here, the researcher established that there was a small non-significant relationship of $24.3 \%$ between strategic control and performance of hunger safety net program. This means that strategic control of the hunger safety net program by Equity bank and National Drought Management Authority has not ensured validation of some premises set during strategic planning stage. It has also not helped in conducting checks during the implementation phase, monitoring of changes occurring in the environment that can threaten the course of action, and being alert to rapidly change the strategy where sudden unexpected events have occurred. This explicates the reason why hunger safety net program has not reached all the pastoralist community households and often has little to negligible economic impact on many households already reached.

\subsection{Conclusions}

The findings of the study concluded that strategic planning had positive influence on the performance of hunger safety net program in Turkana County. As such, it helped the program to meet its objective of reaching the pastoralist community in Turkana using cash payment to reduce hunger and abject poverty. In addition, strategic control created synergy and added value in the definition and shaping of the overall strategy for hunger safety net program, helped in defining engagement rules between Equity bank and National Disaster Management Authority but failed to setting standards as well as assess performance of the two institutions hence did not influence the performance hunger safety net program in Turkana.

\subsection{Recommendations}

This section provides recommendations that are suggested for managerial practice as well as for policy implications.

\subsection{National Government (National Disaster Management Authority)}

The national government through National Disaster Management Authority should conduct formative evaluation of hunger safety net program by assessing its quality, implementation and impact on the beneficiaries. This will 
provide feedback and information for internal improvement and serve as useful information for improving practice, rethinking how to better go about the program and identify future action steps. It should also conduct summative evaluation of the program to provide information on its impact to external agencies in order to keep development partners and stakeholders informed for further improvement of the program. These will help in improving the performance and sustainability of hunger safety net program in Turkana County.

The national government should also increase the amount of cash pay-outs by sourcing for more funds from partners to address the increasing levels of food insecurity in Turkana County as well as aim to reach more households to enhance the overall performance of hunger safety net program in the county.

It should also evaluate its strategic control and alliance with Equity bank to ensure that it positively influences the performance of the hunger safety net program. Positive effects of strategic control and strategic alliance will ensure that hunger safety net program meets its goals and objectives with a view of making the program sustainable.

\subsection{County Government of Turkana}

Turkana County government should supplement the efforts of the national government to eradicate hunger by allocating more resources to hunger safety net program. The county government is closer to the people and should become one of the partners in the implementation of the project objectives with a view of making the program more sustainable.

The county government should come up with other sustainable hunger eradication programs like sinking boreholes and building dams to provide water for farming, animals and domestic consumption. The cash received by the population through hunger safety net program can then be used in farming to produce food locally for the people and livestock.

\subsection{Equity Bank Limited}

Equity bank should install more Automated Teller Machines in other areas outside Lodwar town to reduce the distances people have to walk to access money. It should also open more branches in and increase the number of banking agents in Turkana County for over the counter withdrawals of the hunger safety net program funds. This will enable efficient and fast reception of cash by the beneficiaries.

It should evaluate its technology adoption and partner with a telecommunication firm to issue the beneficiaries of the hunger safety net program with feature phones that can allow them transact on mobile to limit expenses associated with travel to banking halls, ATMs and banking agents. The mobile banking fee (withdrawal charges) should not be expensive and the platform should allow beneficiaries to transact on all mobile networks (M-Pesa, Airtel Money, T-kash etc) without being restricted to use of Equitel.

\subsection{Turkana Pastoralist Community}

The community through local authorities, Community Based Organizations, NGO's, learning/religious institutions and members should be involved in planning, implementation, monitoring and evaluation of the hunger safety net program in order to promote its performance. This will help them to own the program and come up with innovative ways of ensuring its growth and sustainability beyond government and donor existence in the program. Plausibly, the community should actively participate in the program by defining how best it should serve them and share the concerns, challenges and solutions with the implementing organizations for improvement.

\subsection{Development Partners/Sponsors}

The hunger safety net program sponsors should track and audit the use of financial and material resources to ensure accountability of funds donated to the program. This will help the program to avoid misappropriation of funds due to corruption, timely meet its objectives and spur growth and performance of the program.

Sponsors should participate in the need assessment, planning, implementation and evaluation phases of the hunger safety net program. They should check the governance and vision of the program to ensure risks are managed well and succinct delivery of project's economic values to pastoralist community in Turkana.

\subsection{Recommendations for Further studies}

From the findings of the study, it is clear that not every concept on strategic options and program performance was addressed. This knowledge gap has therefore created a valid platform for further scientific inquiry related to this topic. As such, the following few areas of interest have been suggested for further research: A study to find out why strategic control does not influence performance of socio-economic programs like hunger safety net program; A study to establish why the government has not been able to develop sustainable solutions to hunger in ASAL counties; A study to investigate how cash transfers can be used sustainably to address hunger in Turkana County.

\section{REFERENCES}

Abdi, O. A. (2015). Factors Influencing Successful Implementation of Hunger Safety Net Program in the Vulnerable Livelihoods in Northern Kenya: A Case of Wajir County. 
Ali, A. A. (2018). Strategic planning-organizational performance relationship: Perspectives of previous studies and literature review. International Journal of Healthcare Management, 11(1), 8-24.

Attah R., Farhat M., \&Kardan A., (2012).Kenya Hunger Safety Net Program Monitoring and Evaluation Component Qualitative Impact Evaluation Report: 2011-2012.

Beesley, J. (2011). The Hunger Safety Nets Program in Kenya: A Social Protection Case Study. Oxfam GB.

Creswell, J. W., \& Creswell, J. D. (2017). Research design: Qualitative, quantitative, and mixed methods approaches. Sage publications.

Field, A. P. (2018). Discovering Statistics Using IBM SPSS (and sex and drugs and rock 'n'roll). Washington DC: Sage.

Gaturu, P. (2017). Influence of strategic control on organizational performance of Mission Hospitals in Kenya. International Journal of Innovative Research \& Development, 6(6), 163-167.

Goeury, H. (2016, April). Conditional cash transfers (CCTs) and neoliberalism in Latin America. In Paper presented at the conference "Ideas and Transformations in the Americas" held at University College London.

Haji, A. H. (2014). Inter-clan Peace Initiative in Mandera County: A Case of Gurreh and Murulle Communities from 1998-2012. Unpublished Master's Thesis: University of Nairobi, Kenya.

Huho, J., Ngaira, J. \& Harun, O. (2011).Living with Drought: The Case of the Maasai Pastoralists of Northern Kenya.

Kamau, J. W. (2013). Strategic control practices by Syngenta Pollen Limited in Kenya. Unpublished Master thesis, Nairobi: University of Nairobi, Retrieved from http://chss. uonbi. ac. ke.

Kiramana, A. M. (2017). Strategic Planning and Organizational Performance of Equity Bank, Kenya (Master's project, University of Nairobi).

Kuye, O. (2013). Strategic control and corporate entrepreneurship: an empirical study. International Journal of Entrepreneurship and Small Business. 20(2), 2014-232.

Mugenda, A. \& Mugenda, O. (2012). Research methods, qualitative and quantitative approach. Africa Center of Technology (ACTS), Nairobi, Kenya.

Riches, G., \& Silvasti, T. (Eds.). (2014). First world hunger revisited Food charity or the right to food? Springer. Senaratne, S., \& Wijesiri, D. (2008). "Lean Construction as a Strategic Option: Testing its Suitability and Acceptability in Sri Lanka”, Lean Construction Journal, 12(3), 42-49. 